\title{
EXPERIMENTAL AND NUMERICAL INVESTIGATION OF LONG GLASS FIBER REINFORCED POLYPROPYLENE COMPOSITE AND APPLICATION IN AUTOMOBILE COMPONENTS
}

\author{
Shuyong DUAN ${ }^{1,2}$, Xujing YANG ${ }^{3}$, Yourui $\mathrm{TAO}^{4}$, \\ Fuhao $\mathrm{MO}^{5^{*}}$, Zhi XIAO ${ }^{6}$, Kai WEI ${ }^{7}$ \\ ${ }^{1}$ Heibei University of Technology, Tianjin, China \\ ${ }^{2-7}$ State Key Laboratory of Advanced Design and Manufacturing for Vehicle Body, \\ Hunan University, Changsha, China
}

Received 28 September 2015; revised 29 December 2015, 10 March 2016; accepted 4 April 2016; first published online 17 May 2017

\begin{abstract}
Due to the good mechanical performances and design flexibility of Long Glass Fiber Reinforced Polypropylene (LGFRP) composite, it has been increasingly used in the automotive components, in which the LGFRP components are likely to sustain different strain rates loading during a crash event. This study aims to investigate the correlations between the LGFRP and strain rate, which will be applied to crash-worthiness and energy absorbing property analysis of a bumper beam under the longitudinal impact. Firstly, strain rate dependent material properties are determined, for which the experimental procedure is explained in detail on the tensile specimens of long glass fiber and polypropylene matrix based composite configurations. The gained experimental results provide the input parameters for a numerical analysis of specimens. The numerical results of properties are compared with those from tests. The constitutive model that fits for LGFRP is employed to crash-worthiness and energy absorbing property analysis of a bumper beam under the longitudinal impact.
\end{abstract}

Keywords: automobile, weight, stress, numerical simulation, parameter, crash-worthiness, bumper beam.

\section{Notations}

\section{Variables and functions}

$-\sigma_{b}-$ explanation of the ultimate strength;

$-\varepsilon_{b}$ - explanation of the ultimate strain;

$-\sigma_{0}$ - explanation of the ultimate stress of quasistatic conditions;

$-\varepsilon_{0}-$ explanation of the ultimate strain of quasistatic conditions;

$-\dot{\varepsilon}$ - explanation of the strain rate;

- $E_{\text {total }}$ - the total energy absorption of the bumper system;

- $F_{\max }$ - cross section peak force of the crash box.

\section{Abbreviations}

- AOI - amount of moving barrier intrusion;

- GFRP - glass fiber reinforced plastic;

- LGFRP - long glass fiber reinforced polypropylene;

- SEA - specific energy absorption.

\section{Introduction}

At present, with the growing concerns on energy conservation and environmental protection, composites have been increasingly used in aerospace, transportation, defence, sport, etc. because of their advantages of light weight, high strength/weight, stiffness/weight, good corrosion resistant, anti-fatigue performance, vibration attenuation effect, thermostable performance, damagesafety, design flexibility and easy manufacturing (Liu et al. 2013). As one class of typical composites, GFRP has been widely adopted in automobile industry for lightweight design. A composite bus was developed using woven glass/polypropylene composites by Tillotson (Vaidya et al. 2004), which led to over $30 \%$ weight reduction compared with conventional metallic bus. Glass fibers/polypropylene is one kind of GFRP, which offers the potential for rapid manufacturing with low cycle times that allows for medium to high volume production. Moreover, glass fibers/polypropylene can be re-

${ }^{\star}$ Corresponding author. E-mail: fuhaomo@hnu.edu.cn 
cycled (Törnqvist, Baser 2002). Therefore, glass fibers/ polypropylene has been extensively adopted in vehicle components, such as roof door, body panel, floor segment, frame segment, battery access door, and seating system with a weight saving ranging from 40 to $60 \%$, whilst maintains the same or even better performance compared to conventional metallic components (Ning et al. 2009, 2007a, 2007b; Thattaiparthasarathy et al. 2008; Bartus et al. 2006). However, automobile components are likely to sustain rate loading during a crash event. Accurate constitutive model under different strain rates is important for numerical simulations in vehicle design and crashworthiness assessment (Brown et al. 2010). Thus, it is necessary to investigate the effect of strain rate on the performance of the material.

Several previous studies investigated the effect of strain rate on the mechanical properties of GFRP. The strength, fracture strain, and the impact strength of the GFRP increase with increasing strain rate, which is confirmed by Reis et al. (2012), where reported dynamic tensile tests for GFRP and observed that the mechanical properties of the GFRP show a strain-rate dependency. Papadakis et al. (2004) investigated the effect of $\dot{\varepsilon}$ on the tensile and shear properties of a continuous glass fibers and polypropylene at various crosshead speeds. They observed that the Young's modulus increases with increasing loading rate whilst the ultimate strength decreases. The shear strength was reported to increase while the shear modulus decreases with increasing $\dot{\varepsilon}$. Bai et al. (2000) studied the effect of strain rate on tensile properties of glass bead/high density polyethylene composites. The studied results shown that both the Young's modulus and tensile strength increase with increasing strain rate. Şerban et al. (2013) investigated the influence of strain rate on the tensile properties of a PA 12-based polymer composite materials at strain rate ranging from 0.00028 to $9.4 \mathrm{~s}^{-1}$. They noted that the tensile strength increases with increasing strain rate. Bonnet (Brown et al. 2009) reported on the characterization of the mechanical properties of glass/polypropylene commingled woven fabric unbalanced 4:1 weave composite and a short glass fiber reinforced polypropylene composite at strain rate ranging from $10^{-1}$ to $100 \mathrm{~s}^{-1}$. The results of weave composite show that the average tensile and shear modulus decrease with increasing strain rate while the tensile and shear strength increase. The polypropylene composite exhibits marginal strain rate sensitivity. There is a high level of data scatter, which is partly attributed to the test setup and inertial effects.

Some researchers investigated constitutive relationship of composite materials (Brown et al. 2010, Daniel et al. 2011; Hufenbach et al. 2011). Daniel et al. (2011) researched the quasi-static and dynamic behaviour of composite materials and developed/expanded failure theories to describe static and dynamic failure under multi-axial states of stress. The results show that the partially interactive criteria (Hashin-Rotem, Sun, and Daniel) theory is in excellent agreement with experimental results. Hufenbach et al. (2011) investigated orthotropic strain rate dependent material parameters of e-glass fiber based multi-layered weft knitting with a thermosetting epoxy matrix and a thermoplastic polypropylene matrix. The results of both configurations are used to determine the parameters for a strain rate dependent model based on a modified Johnson-Cook approach.

Although some investigations on constitutive models of composites are reported in the above literatures, most of the above studies focus on thermosetting materials and few investigations focus on glass fibers and polypropylene composite, especially on LGFRP. LGFRP as a new composite has favourable mechanical and shaping properties when applied in bumper beam. It is important to investigate the effect of strain rate on the mechanical properties and corresponding constitutive model of LGFRP for the automobile component design and crashworthiness assessment. This paper investigates the effects of strain rate on the response of LGFRP in tensile loading, and the corresponding constitutive model is discussed. Furthermore, the constitutive model is applied to the numerical analysis of the bumper beam.

\section{Experimental Setup}

\subsection{Material, Fabrication Process}

The LGFRP used in this study is a mixture of long e-glass fibers and polypropylene composite with a nominal 50\% glass fibers weight fraction. The length of glass fibers in LGFRP is about $45 \mathrm{~mm}$ and the radius of the glass fibers is $13 \mu \mathrm{m}$. The LGFRP is manufactured by the air lay process technology, in which the fibers are suspended in an air stream and then blown or forced onto a continuously moving belt where the web is formed. Therefore, air laying web technology can be used to produce the three dimensional structure of fiber mat, in which the fiber arrangement is non-direction as shown in Figure 1. The strength ratio of longitudinal and transverse for the product made of the fiber mat can reach 1:1. As shown in Figure 1, the white fibers are the long e-glass fibers and the blank fibers are the polypropylene fibers.

The preparation process of the experimental materials is as follows. Procuring combination mat is stacked ply-by-ply in an infrared oven, and preheated at a temperature of $200{ }^{\circ} \mathrm{C}$. The time for heat preservation is $2 \mathrm{~min}$. The stack is then rapidly transferred to a preheated tool $\left(70-80^{\circ} \mathrm{C}\right)$ which is installed in a stroking servo-hydraulic press. The tool is closed and pressure holding time is $30 \mathrm{~s}$. Then the composite plates are obtained.

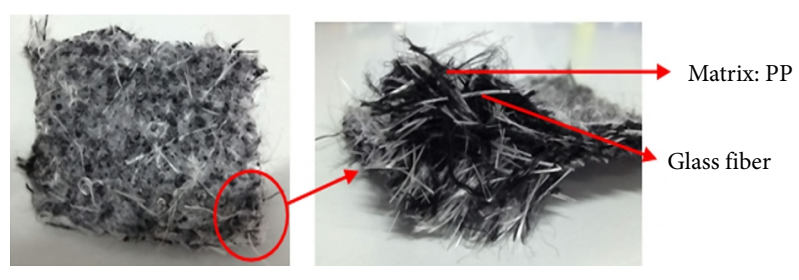

Figure 1. Combination mat (magnification is 30) 


\subsection{Specimens and Test Procedure}

Since there is no official test method/code for LGFRP material, based on actual experiment need, authors select two type specimens used in the paper for the consideration of Chinese Standard GB/T 1447-2005. The dumbbell tensile specimens are cut from the flat planes, as shown in Figure 2 and the thickness of tensile specimen is $3 \mathrm{~mm}$. The density of tensile specimens is $0.00109 \mathrm{~g} / \mathrm{mm}^{3}$. Both quasi-static tests and dynamic tensile tests are conducted in a fatigue-testing machine (MTS 647 Hydraulic Wedge Grip). The speed $v$ of clamp is set according to the strain rate. To prevent the fracture of specimens in chuck position in tensile tests, the clamping parts of the specimens are reinforced by aluminium alloy plates with $1 \mathrm{~mm}$ thickness. The tests in the same conditions are repeated five or more than five times to obtain the reliable experimental data. Then a revised stress-stain curve is obtained by taking the average value of the three similar stress-strain curves.

a)

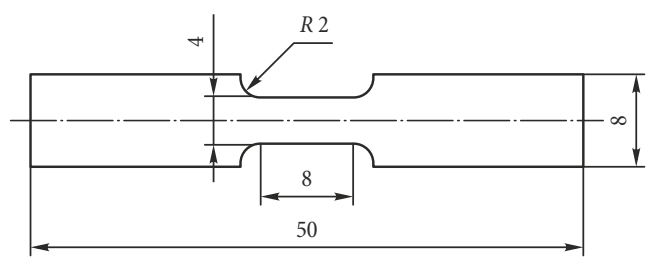

b)

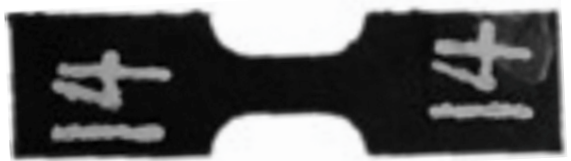

Figure 2. LGRFP tensile specimen shape and dimension [mm] (a) and typical tensile test specimen 1 (b)

\section{Characterization of material properties}

\subsection{The strain-stress Curves}

After processing the tensile experimental data, the stress-strain curves of LGFRP at different strain rate are obtained as shown in Figure 3. When strain rates are equal to $0.0009 \mathrm{~s}^{-1}$ and $0.0095 \mathrm{~s}^{-1}$, the stress-strain responses of this material are non-linear with premature yielding followed by maximum peak stress and strainsoftening. At strain rate $0.097-50.25 \mathrm{~s}^{-1}$, the stressstrain responses are approximately linear elastic up to the maximum stress point followed by abrupt failure. The stress is decreased obviously after the maximum stress; it may be attributed to the damage accumulation. The breakage of the matrix with bubbles, shrinkage and other defects firstly arises after the ultimate stress. In addition, the carrying capacities of the specimens begin to weaken, part of the fibers are pulled out and fractured with the load increasing, until all the fibers of fracture surface are pulled out or fractured. The material stressstrain responses may be attributed to the time dependent. At lower strain rates, the specimens have time to distribute the load and undergo steady damage accumulation, therefore, the material stress-strain responses with strain-softening under strain rates $0.0009 \mathrm{~s}^{-1}$ and $0.0095 \mathrm{~s}^{-1}$ are easily observed. However, at high strain rate the specimens have less time to respond and fail after limited yielding.

The ultimate strength and ultimate strain of tensile test at different strain rate are presented in Table 1 and Figure 4 . The tensile ultimate strength increases from 100.2 to $184.3 \mathrm{MPa}$ and ultimate strain increases from 0.038 to 0.084 with increasing strain rate $\left(0.0009-50.25 \mathrm{~s}^{-1}\right)$.

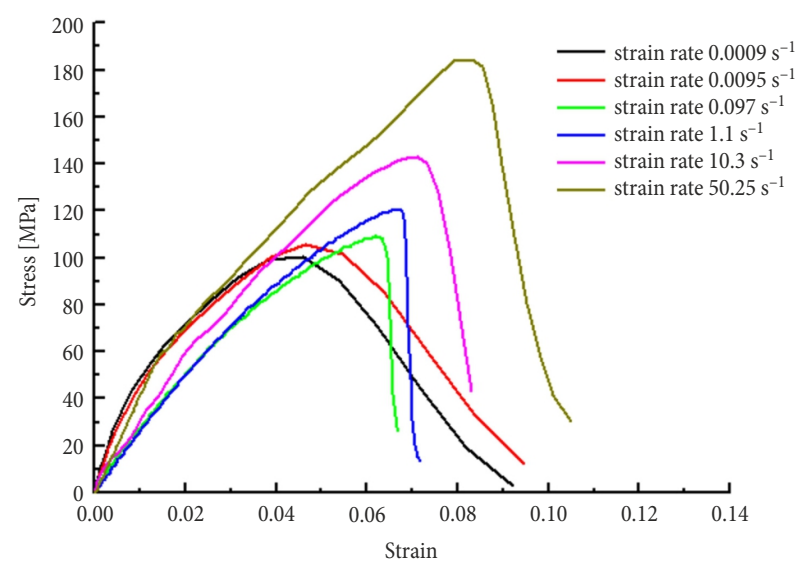

Figure 3. Typical tensile stress-strain curves for LGFRP at different strain rate

a)

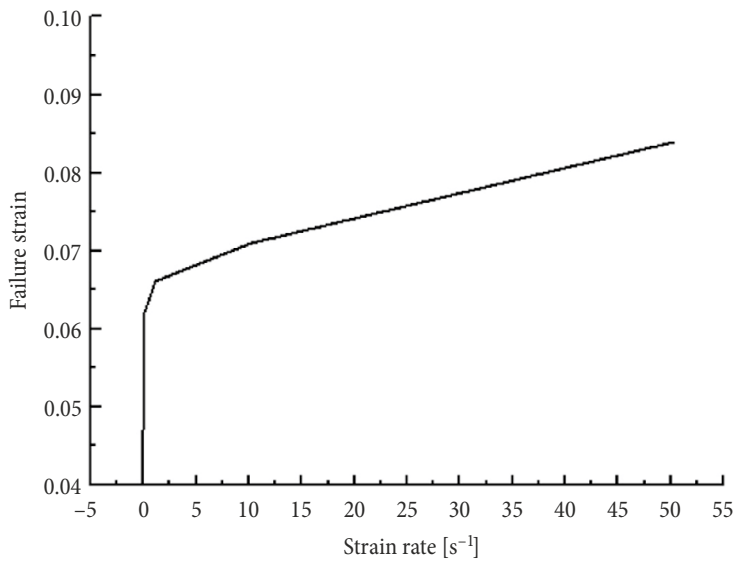

b)

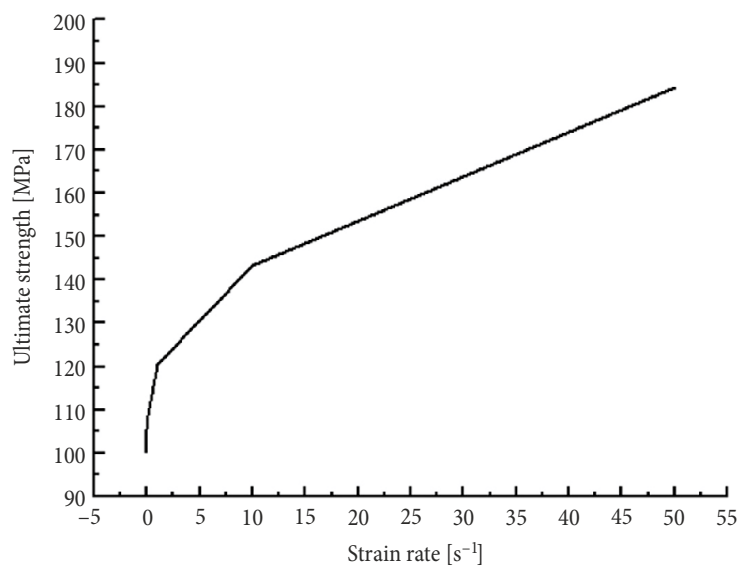

Figure 4. The failure strain-strain rate curve of tensile specimens (a) and ultimate strength-strain rate curve (b) 
In the wake of increase in strain rate $\left(0.0009-50.25 \mathrm{~s}^{-1}\right)$, ultimate strength and ultimate strain has become more sensitive to strain rate. The ultimate strength increases significantly up to $183.9 \%$ from 0.0009 to $50.25 \mathrm{~s}^{-1}$. The ultimate strength follows a similar trend with an increase of $221.05 \%$ from 0.0009 to $50.25 \mathrm{~s}^{-1}$. The effect of strain rate on ultimate strength and ultimate strain may be attributed to a combination of several factors, including the viscoelastic nature of the polymeric matrix, the performance and arrangement of glass fiber, the interface between the matrix and reinforced fiber, etc. (Groves et al. 1993). Furthermore, the strain rate sensitivity of the tensile strength can also be attributed to the strain rate dependence of the glass fibers in fiber dominated loading mode, as suggested by Okoli (2001).

Table 1. Tensile properties of LGFRP at different strain rate

\begin{tabular}{|c|c|c|}
\hline Strain rate $\left[\mathrm{s}^{-1}\right]$ & $\begin{array}{c}\text { Ultimate strength } \sigma_{b} \\
{[\mathrm{MPa}]}\end{array}$ & $\begin{array}{c}\text { Ultimate strain } \\
\varepsilon_{b}\end{array}$ \\
\hline 0.0009 & 100.2 & 0.038 \\
\hline 0.0095 & 105.4 & 0.047 \\
\hline 0.097 & 108.6 & 0.062 \\
\hline 1.1 & 120.5 & 0.066 \\
\hline 10.3 & 143.3 & 0.071 \\
\hline 50.25 & 184.3 & 0.084 \\
\hline
\end{tabular}

\subsection{Material visco-plastic model}

The experimental results shown in section 2.1 indicate that the properties of LGFRP are sensitive to the $\dot{\varepsilon}$ in the tensile tests. In this study, a homogenization procedure is adopted, and the base materials of the composite are considered homogeneous in microscope. The constitutive relations associated with $\dot{\varepsilon}$ for the LGFRP is expressed as (LSTC 2007):

$$
\sigma\left(\varepsilon_{0}, \dot{\varepsilon}\right)=\sigma_{0}\left(\varepsilon_{0}\right)\left(1+\left(\frac{\dot{\varepsilon}}{C}\right)^{1 / P}\right),
$$

where: $1+\left(\frac{\dot{\varepsilon}}{C}\right)^{1 / P}$ is the Cowper-Symonds model (LSTC 2007) which scales the yield stress with the factor; $C$ and $P$ are strain rate parameters.

The value of $C$ and $P$ under different strain rates can be calculated by Equation (1) based on experimental results, in which the values of $C$ and $P$ are 80 and 2.778, respectively.

In order to prove the effectiveness of the proposed constitutive model, Figure 5 shows the experimental results (indicated by dotted lines) for the specimens under the tension test compared with the visco-plastic constitutive model (indicated by solid lines). From Figure 5 and Table 2, we can get the maximum relative errors of $\sigma_{b}, \varepsilon_{b}$ for experimental results and the theoretical results of the tensile specimens at different strain rate, which are 3.3 and $19.4 \%$, respectively. The curves obtained by the visco-plastic constitutive model are in excellent agree-

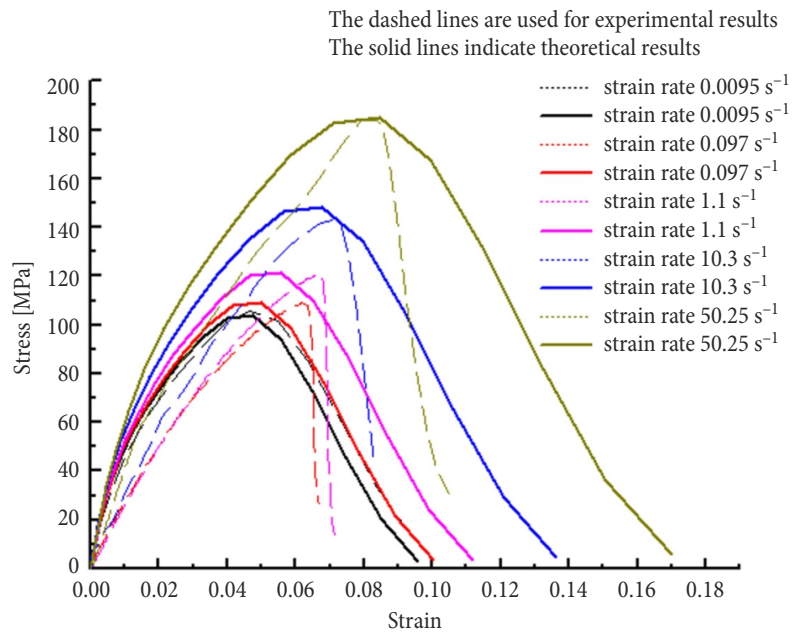

Figure 5. Comparison of theoretical failure envelopes and experimental results for LGFRP under different strain rates: the tensile stress-strain curves for LGFRP

Table 2. The error analysis of experimental results and the theoretical results for the tensile specimens at different strain rate

\begin{tabular}{|c|l|c|c|}
\hline $\begin{array}{c}\text { Strain } \\
\text { rate }\left[\mathrm{s}^{-1}\right]\end{array}$ & \multicolumn{1}{|c|}{ Specimen 1 } & $\begin{array}{c}\text { Ultimate strength } \\
\sigma_{b}[\mathrm{MPa}]\end{array}$ & $\begin{array}{c}\text { Ultimate } \\
\text { strain } \varepsilon_{b}\end{array}$ \\
\hline \multirow{2}{*}{0.0095} & $\begin{array}{l}\text { the theoretical } \\
\text { results }\end{array}$ & 104.1 & 0.048 \\
\cline { 2 - 4 } & *error analysis & $1.2 \%$ & $2.1 \%$ \\
\hline \multirow{2}{*}{0.097} & $\begin{array}{l}\text { the theoretical } \\
\text { results }\end{array}$ & 109.1 & 0.05 \\
\cline { 2 - 4 }${ }^{*}$ error analysis & $0.5 \%$ & $19.4 \%$ \\
\hline \multirow{2}{*}{1.1} & $\begin{array}{l}\text { the theoretical } \\
\text { results }\end{array}$ & 121.6 & 0.056 \\
\cline { 2 - 4 }${ }^{*}$ error analysis & $0.9 \%$ & $15.2 \%$ \\
\hline \multirow{2}{*}{10.3} & $\begin{array}{l}\text { the theoretical } \\
\text { results }\end{array}$ & 148.1 & 0.068 \\
\cline { 2 - 4 } *error analysis & $3.3 \%$ & $4.2 \%$ \\
\hline \multirow{2}{*}{50.25} & $\begin{array}{l}\text { the theoretical } \\
\text { results }\end{array}$ & 184.9 & 0.085 \\
\cline { 2 - 4 } & *error analysis & $0.3 \%$ & $1.2 \%$ \\
\hline
\end{tabular}

Note: *error analysis represents the relative error of experimental results and the theoretical results for the tensile specimens.

ment with experimental results. Therefore, the viscoplastic constitutive model can be used to develop strain rate dependent material model required in static and dynamic numerical calculation of LGFRP.

The theory is very effective and useful for engineering design. New material can be easily implemented by simply conducting a few macroscopic tests on LGFRP and establishing the strain rate dependence of mechanic properties for LGFRP and developing strain rate dependent material model required in finite element codes for accurate structural modelling and designing of components made from LGFRP subjected to dynamic impact loads. 


\section{Establishment of finite element model and experimental validation}

\subsection{Numerical simulations}

In order to get the clear strain contours, the larger size dumbbell tensile specimen (Figure 6a, specimen 2) can be selected for the quasi-static research. The specimen 1 (Figure 2) can be selected for the dynamic research in order to get the high tensile speed. According to the experimental conditions the LS-DYNA model is modeled, which is represented in Figure $6 \mathrm{~b}$ and material properties of LGFRP specimen are shown in Table 3. Mat24 is designed specifically to handle isotropic materials and the detailed definition of parameters is given in LSTC (2007). The finite element model is meshed using a fully integrated linear shell element of $1 \times 1 \mathrm{~mm}$ square element size. The specimen is a modelled with a total of 2481 elements, and the constant thickness is $3 \mathrm{~mm}$. The tensile speed is $150 \mathrm{~mm} / \mathrm{s}$.

a)

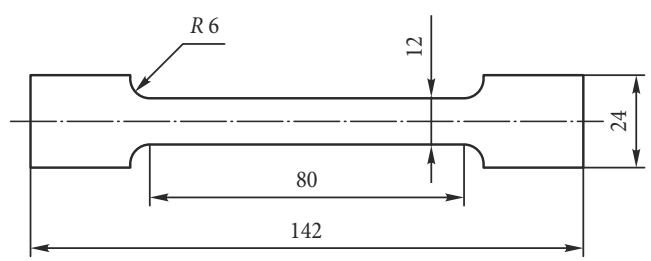

b)

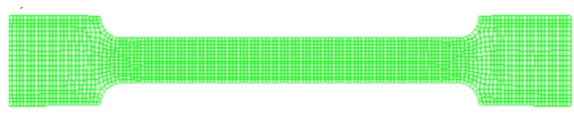

Figure 6. LGFRP dumbbell tensile specimen shape and dimension [mm] (a) and LS-DYNA model of the LGFRP specimen (b)

Table 3. Material properties of LGFRP specimen

\begin{tabular}{|c|c|c|c|c|c|}
\hline Property & $\begin{array}{c}\text { Mass } \\
\text { density } \\
{[\mathrm{g} / \mathrm{cm}]}\end{array}$ & $\begin{array}{c}\text { Young's } \\
\text { modulus } \\
{[\mathrm{GPa}]}\end{array}$ & $\begin{array}{c}\text { Poisson's } \\
\text { ratio }\end{array}$ & $\begin{array}{c}\text { Yield } \\
\text { stress } \\
{[\mathrm{MPa}]}\end{array}$ & $\begin{array}{c}\text { Failure } \\
\text { strain }\end{array}$ \\
\hline $\begin{array}{l}\text { Experimen- } \\
\text { tal value }\end{array}$ & 1.09 & 10 & 0.3 & 36.5 & 0.0356 \\
\hline
\end{tabular}

\subsection{Experimental verification and discussion}

In order to verify the material visco-plastic model characterized using the finite element analysis in section 3.1, the tensile tests are conducted. These tests are carried out on the SANS 5305 loading machine at the room temperature. Furthermore, strain evaluation is performed with a digital image correlation technique, which proved to be an efficient strain recording method for thermoplastic polymers at high strains (Parsons et al. 2004, 2005; Fang et al. 2006; Jerabek et al. 2010). Images are recorded with a high speed camera with resolution of $1624 \times 1224$ pixels for the tensile tests, focal length with $200 \mathrm{~mm}$ and capable of recording with 200000 frames/sec. The images are processed with the help of ARAMIS software by GOM (http://www.gom.com/3d-software/gom-system-software/ aramis-professional.html) using grey-scale correlation.
Since the dumbbell tensile specimens (the same size with the simulation specimen) are prepared well, a white paint layer is airbrushed on the surface of the specimens before the random speckle pattern (black paint) is applied (Figure 7) in order to eliminate possible erroneous reading during grey-scale correlation. The $150 \mathrm{~mm} / \mathrm{s}$ cross-head travel speed are used in preliminary tests. Moreover, a limitation of the optical method for strain recording is discovered during the tensile tests. As demonstrated above, the material requires an opaque layer of paint to be applied before the speckle pattern. This layer is proved to have a relatively low fracture strain (around 12.6\%) compared to the base material. As deformation increased, the paint layer will disintegrate and the post-processing software could not keep track of the pixel, thus, resulting in erroneous readings after a certain strain. Hence, no fracture strain is recorded for the tested LGFRP.

Representative photographs at the tensile tests are taken from the testing of the LGFRP dumbbell specimens (Figure 7). The contours of strain are obtained, which clearly show the macroscopic features of the fracture mode (Figure 8a). Figure $8 \mathrm{a}$ also shows the major macroscopic damage mechanisms of tensile LGFRP specimens include matrix cracking, fiber or fiber bundle breakage. The changes of strain contours with load time history, the position where the maximum strain appears, propagation and the situation of the fracture surface of experiment are the same as those of simulation results. The ultimate strength, ultimate strain and peak force obtained by experiment and simulation are depicted in $\mathrm{Ta}-$ ble 4 . The fractional errors between experimental values of ultimate strength (94 MPa), ultimate strain (0.036) and peak force $(3650.4 \mathrm{~N})$ and simulation data of ultimate strength (95.51), ultimate strain (0.036) and peak force $(3815.1 \mathrm{~N})$ are about $1.6,0$ and $4.5 \%$, respectively. The experimental and simulation results of specimen 1 for the other strain rates are shown in Table 5. The relative errors range of ultimate strength, ultimate strain and peak force between the experimental and simulation results of tensile specimens 1 at different strain rates are $0.8-7.2 \%, 2.6-17.8 \%$ and $1.3-7.6 \%$, respectively. a)
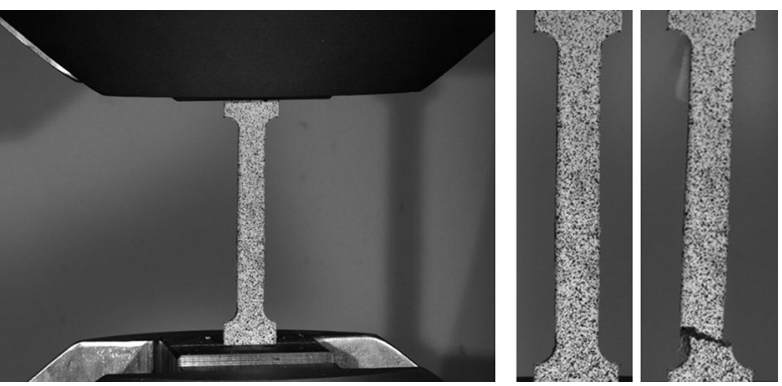

Figure 7. Spray pattern specimen: a - prepared specimen clamped in machine grips; b - HS camera images from test initiations with intact paint layer (left) and test end with cracked paint layer (right) 
a)

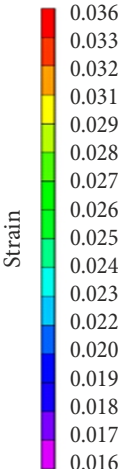

b)

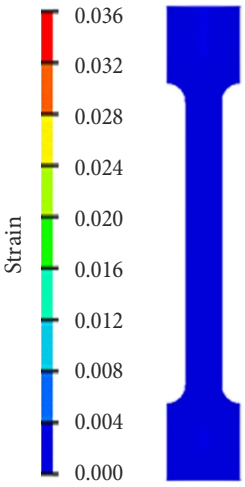

$t=1 \mathrm{~s}$
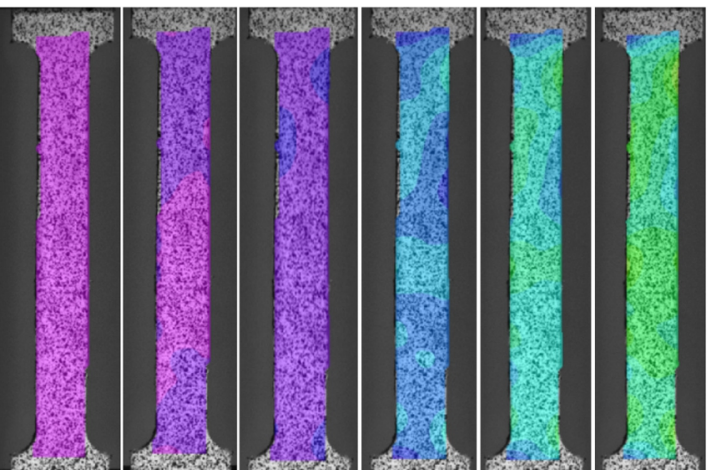

$t=24 \mathrm{~s}$

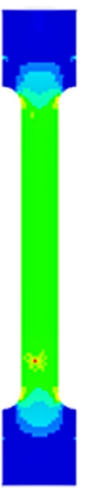

$t=24 \mathrm{~s}$

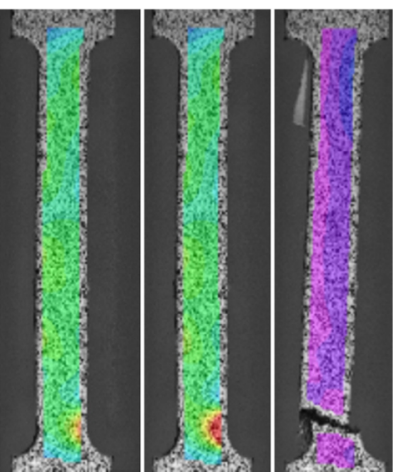

$t=31 \mathrm{~s} \quad t=32 \mathrm{~s}$

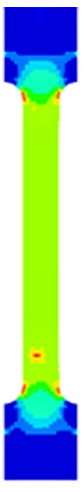

$t=30 \mathrm{~s}$

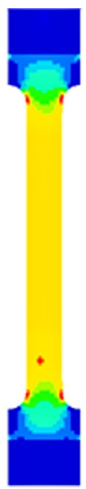

$t=31 \mathrm{~s}$ $t=32 \mathrm{~s}$

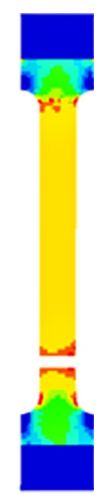

Figure 8 . The strain contours of the tensile specimen: a - the strain contours for experimental test; $\mathrm{b}$ - the strain contours for numerical simulations

The maximum relative errors of ultimate strength, ultimate strain and peak force for the experimental results and simulation results of tensile specimens 1 at different strain rates are $11.5,17.8$ and $7.6 \%$, which can meet the precision requirement for engineering application. Overall, the responses predicted in finite element analysis are in accordance with those in experimental tests, which verifies that the proposed approach to the characterization of material visco-plastic model is feasible and the visco-plastic constitutive model can be used for the crashworthiness analysis on the macroscopic structure.

Table 4. The error analysis of experimental results and the simulation results for the tensile specimens 2 at strain rate $0.0009\left[\mathrm{~s}^{-1}\right]$

\begin{tabular}{|c|l|c|c|c|}
\hline $\begin{array}{c}\text { Strain } \\
\text { rate } \\
{\left[\mathrm{s}^{-1}\right]}\end{array}$ & Specimen 2 & $\begin{array}{c}\text { Ultimate } \\
\text { strength } \sigma_{b} \\
{[\mathrm{MPa}]}\end{array}$ & $\begin{array}{c}\text { Ultimate } \\
\text { strain } \varepsilon_{b}\end{array}$ & $\begin{array}{c}\text { Peak force } \\
{[\mathrm{N}]}\end{array}$ \\
\hline \multirow{2}{*}{0.0009} & $\begin{array}{l}\text { experimental } \\
\text { value }\end{array}$ & 94 & 0.036 & 3650.4 \\
\cline { 2 - 5 } & $\begin{array}{l}\text { simulation } \\
\text { value }\end{array}$ & 95.51 & 0.036 & 3815.1 \\
\cline { 2 - 5 } & $\begin{array}{l}\text { error } \\
\text { analysis }\end{array}$ & $1.6 \%$ & $0 \%$ & $4.5 \%$ \\
\hline
\end{tabular}

Table 5. The error analysis of experimental results and the simulation results for the tensile specimens 1 at different strain rate

\begin{tabular}{|c|c|c|c|c|}
\hline $\begin{array}{c}\text { Strain } \\
\text { rate } \\
{\left[\mathrm{s}^{-1}\right]} \\
\end{array}$ & Specimen 1 & $\begin{array}{c}\text { Ultimate } \\
\text { strength } \sigma_{b} \\
{[\mathrm{MPa}]}\end{array}$ & $\begin{array}{l}\text { Ultimate } \\
\text { strain } \varepsilon_{b}\end{array}$ & $\begin{array}{c}\text { Peak force } \\
{[\mathrm{N}]}\end{array}$ \\
\hline \multirow[t]{2}{*}{0.0009} & $\begin{array}{l}\text { simulation } \\
\text { value }\end{array}$ & 95.6 & 0.037 & 1320.3 \\
\hline & ${ }^{*}$ error analysis & $4.6 \%$ & $2.6 \%$ & $4 \%$ \\
\hline \multirow{2}{*}{0.0095} & $\begin{array}{l}\text { simulation } \\
\text { value }\end{array}$ & 97.8 & 0.044 & 1389.9 \\
\hline & ${ }^{*}$ error analysis & $7.2 \%$ & $6.5 \%$ & $1.3 \%$ \\
\hline \multirow{2}{*}{0.097} & $\begin{array}{l}\text { simulation } \\
\text { value }\end{array}$ & 102.1 & 0.051 & 1419.7 \\
\hline & ${ }^{*}$ error analysis & $6 \%$ & $17.8 \%$ & $7.6 \%$ \\
\hline \multirow[t]{2}{*}{1.1} & $\begin{array}{l}\text { simulation } \\
\text { value }\end{array}$ & 119.5 & 0.055 & 1601.3 \\
\hline & ${ }^{*}$ error analysis & $0.8 \%$ & $17.4 \%$ & $3.3 \%$ \\
\hline \multirow{2}{*}{10.3} & $\begin{array}{l}\text { simulation } \\
\text { value }\end{array}$ & 156.1 & 0.0063 & 2270.9 \\
\hline & * error analysis & $8.9 \%$ & $10 \%$ & $2.3 \%$ \\
\hline \multirow[t]{2}{*}{50.25} & $\begin{array}{l}\text { simulation } \\
\text { value }\end{array}$ & 205.5 & 0.073 & 2566 \\
\hline & *error analysis & $11.5 \%$ & $14.1 \%$ & $6.3 \%$ \\
\hline
\end{tabular}

Note: * error analysis represents the relative error of experimental results and the simulation results for the tensile specimens 1 . 


\section{Applied to bumper beam crashworthiness analysis}

\subsection{Establishment of finite element model}

The finite element analysis is further carried out to quantify the crashworthiness performance of the bumper beam made of LGFRP. The simulation is performed according to the regulatory requirements of the United Nations Economic Commission for Europe Regulation No 42 (UN 1980); we can conclude that the crashworthiness evaluation methods for low-speed collision of front bumper are mainly on two aspects of the bumper system from the crash energy absorption characteristics and dynamic response characteristics to proceed. In accordance with this evaluation, the following evaluation index is defined:

- The total energy absorption of the bumper system. When cars collide in low-speed, the impact energy is absorbed by bumper system as much as possible. Thus, the bumper system can reduce the energy transferred to the rear, and protect the whole structure of the vehicle. Thus, the total energy absorption is an important indicator for beam. In this paper, the total energy absorption is the sum energy absorption of the beam and crash boxes.

- Cross section peak force of the crash box. The striking force transferred to the rear of the car may be reduced when the $F_{\max }$ is smaller, so as to make the overall car structure is more stable.

- AOI. The damage to the rear part of the beam may be reduced, and the integrity of the automobile engine may also be maintained when the AOI is smaller, the beam deformation is smaller.

- The length of contact period between the beam and impactor in a crash. Longer contact period means better cushioning property of the anticollision crossbeam and a smaller impact force to the driver, and moreover reducing the impact strength to pedestrian.

By means of numerical simulations of deformation progress, it is possible to understand how the energy is distributed in the transverse beam structure. A nonlinear finite element simulation, with a simplified bumper beam model as displayed in Figure 9, is carried out using the commercial code Hypermesh/Explicit version 10.0. The model is comprised of four parts, three rigid parts (one rigid wall and the two longitudinal crash boxes, the material parameters of the two longitudinal crash boxes are shown in Table 6), and one deform-able bumper beam. The rigid bodies are modelled as discrete rigid surfaces in order to create higher mesh density at critical contact areas. The bumper beam is made of LGFRP (the mainly material parameters are shown in Table 3). The thickness of LGFRP beam is $5 \mathrm{~mm}$. The finite element model is meshed using a fully integrated linear shell element of square element size. A mass of $1425 \mathrm{~kg}$ is uniformly distributed on the four sides of the two crash boxes in order to simulate the vehicle mass. In the front-end collision, the $X$ direction shown in Figure 9 is free, which is the same as actual test. The rigid wall is

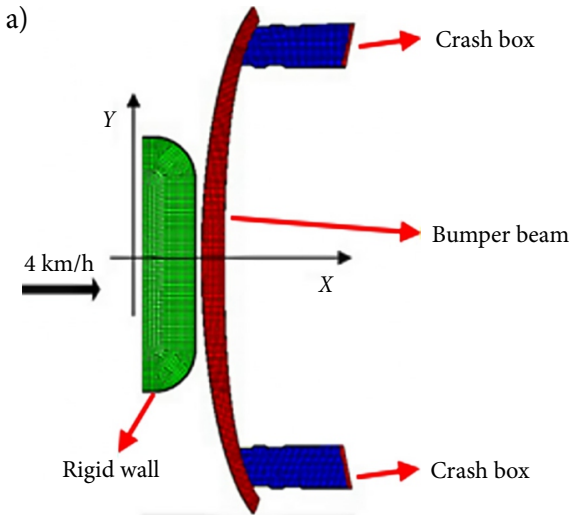

b)

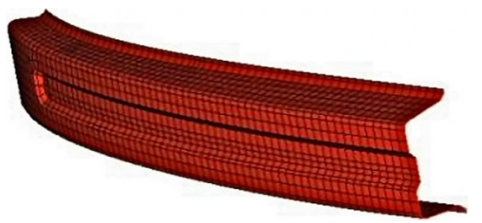

Figure 9. Finite element model of the bumper beam: a - longitudinal pendulum impact at $4 \mathrm{~km} / \mathrm{h}$; $\mathrm{b}$ - the cross sectional shape

moving on the front longitudinally with an initial velocity of $4 \mathrm{~km} / \mathrm{h}$ (that is, longitudinal pendulum impact). To evaluate bumper performance at low velocity impact, different organizations use different set of standards. The present study is not conducted to meet some specific standard and does not consider the entire bumper subsystem except for the bumper beam performance. In order to compare with metallic material solutions, the finite element model of the bumper beam made of steel material DP1400 is established (the material parameters are shown in Table 6). The thickness of steel beam is $2.2 \mathrm{~mm}$. The same loading, boundary conditions and geometry except the thickness are used in the simulation of steel beam and composite beam.

Table 6. The material parameters of the bumper beam with steel and crash boxes

\begin{tabular}{|l|c|c|c|c|}
\hline \multicolumn{1}{|c|}{ Terms } & $\begin{array}{c}\text { Density } \rho \\
{\left[\mathrm{kg} / \mathrm{mm}^{3}\right]}\end{array}$ & $\begin{array}{c}\text { Young's } \\
\text { modulus } E \\
{[\mathrm{GPa}]}\end{array}$ & $\begin{array}{c}\text { Poisson's } \\
\text { ratio } \mu\end{array}$ & $\begin{array}{c}\text { Yield } \\
\text { stress } \sigma_{s} \\
{[\mathrm{MPa}]}\end{array}$ \\
\hline $\begin{array}{l}\text { Bumper } \\
\text { beam }\end{array}$ & $7.86 \cdot 10^{-6}$ & 200 & 0.28 & 1000 \\
\hline $\begin{array}{l}\text { Crash } \\
\text { boxes }\end{array}$ & $7.83 \cdot 10^{-6}$ & 200 & 0.3 & 414 \\
\hline
\end{tabular}

\subsection{Discussion of the results of numerical simulation}

Based on the crashworthiness criteria above mentioned, a composite bumper beam is proposed to develop a vehicle with a lighter bumper beam. It is now to compare the obtained composite bumper beam solution with steel solutions in terms of impact $S E A=\frac{E_{\text {total }}}{\text { mass }}$, which is defined as the $E_{\text {total }}$ divide by the total mass of bumper 
Table 7. Results of performance for the bumper beam with LGFRP composite and steel material

\begin{tabular}{|c|c|c|c|c|c|c|c|}
\hline \multicolumn{2}{|c|}{ Specimen No } & \multicolumn{2}{|c|}{ Mass [kg] } & $\mathrm{AOI}[\mathrm{mm}]$ & $F_{\max }[\mathrm{kN}]$ & Impact time [ms] & SEA $[J / K g]$ \\
\hline \multirow{2}{*}{ Specimen 3} & Steel bumper beam & 3.989 & \multirow{2}{*}{5.296} & \multirow{2}{*}{32} & \multirow{2}{*}{19.92} & \multirow{2}{*}{80} & \multirow{2}{*}{81.34} \\
\hline & Steel crash box & 1.307 & & & & & \\
\hline \multirow{2}{*}{ Specimen 4} & LGFRP bumper beam & 1.267 & \multirow{2}{*}{2.574} & \multirow{2}{*}{43} & \multirow{2}{*}{11.23} & \multirow{2}{*}{120} & \multirow{2}{*}{167} \\
\hline & Steel crash box & 1.307 & & & & & \\
\hline Specimen 5 & LGFRP bumper beam & 1.267 & 2.2 & 43 & 8.6 & 120 & 195 \\
\hline
\end{tabular}

beam, $F_{\max }$ AOI and collision time. The performance results for the bumper beam with composite and steel material are shown in Table 7.

It can be seen from Table 7, the SEA of specimen 3 (steel bumper beam and steel crash box) and specimen 4 (LGFRP bumper beam and steel crash box) are 81.34 and $167.1 \mathrm{~J} / \mathrm{kg}$ in longitudinal pendulum impact, respectively. It can be noted that the SEA of composite bumper beam (specimen 4) is the approximately as 2 times as that of specimen 3 . The impact time of specimens $4(120 \mathrm{~ms})$ is the nearly as 1.5 times as that of specimen 3 . The $F_{\max }$ of specimen $4(11.23 \mathrm{kN})$ significantly lower than that of specimen $3(19.92 \mathrm{kN})$. Although the values of AOI for specimen $3(32 \mathrm{~mm})$, specimen $4(43 \mathrm{~mm})$ are all meet the design requirements, the AOI of specimens 4 is 1.3 times as that of specimen 3 . The mass of specimen $4(2.574 \mathrm{~kg})$ is much lighter than that of specimen $3(5.296 \mathrm{~kg})$. From Table 7 , we can also get that the AOI and collision time of the specimens 4 and 5 with two kinds of considered material for crash box are the same. The SEA of specimen $5(195 \mathrm{~J} / \mathrm{kg})$ is 1.17 times as that of specimen 4 $(167 \mathrm{~J} / \mathrm{kg})$. The $F_{\max }$ of specimen $5(8.6 \mathrm{kN})$ is 0.77 times as that of specimen $4(11.23 \mathrm{kN})$. The mass of specimen $5(2.2 \mathrm{~kg})$ is about $0.37 \mathrm{~kg}$ lighter than that of specimen $4(2.574 \mathrm{~kg})$. Therefore, the whole performance of the specimen 5 is much better than that of specimens 3 and 4. After a comprehensive performance comparison, the various performance of the composite bumper beam has reached the requirement of the crash regulations, and some performance index is even better than that of steel bumper beam. Hence replacing steel bumper beam with composite bumper beam is feasible.

\section{Conclusions}

The effect of strain rate on the mechanical properties of LGFRP has been reported for the strain rate range from 0.00 to $50.25 \mathrm{~s}^{-1}$.

The experimental results show that the tensile ultimate strengths and ultimate strain increase with increasing strain rate. Then, based on the experimental results, a visco-plastic constitutive model is proposed, which is well correlated with the experimental test results regarding the stress-strain curves in various strain rates.

Meanwhile, the SEA of the bumper beam remarkably increase and the section force of the crash box significantly decrease.

Furthermore, a $51-58 \%$ saving of bumper beam weight is achieved using the LGFRP compared to its predecessor made of the traditional metal materials.
It is recommended that the visco-plastic material model can be used for other lightweight vehicle structure made of LGFRP composites.

\section{References}

Bai, S.-L.; Cao, K.; Chen, J.-K.; Liu, Z.-D. 2000. Tensile properties of rigid glass bead/HDPE composites, Polymers \& Polymer Composites 8(6): 413-418.

Bartus, S. D.; Vaidya, U. K.; Ulven, C. A. 2006. Design and development of a long fiber thermoplastic bus seat, Journal of Thermoplastic Composite Materials 19(2): 131-154. https://doi.org/10.1177/0892705706062184

Daniel, I. M.; Werner, B. T.; Fenner, J. S. 2011. Strain-rate-dependent failure criteria for composites, Composites Science and Technology 71(3): 357-364.

https://doi.org/10.1016/j.compscitech.2010.11.028

Fang, Q.-Z.; Wang, T. J.; Li, H.-M. 2006. Large tensile deformation behavior of PC/ABS alloy, Polymer 47(14): 5174-5181. https://doi.org/10.1016/j.polymer.2006.04.069

GB/T 1447-2005. Fiber-Reinforced Plastics Composites. Determination of Tensile Properties. Code of China (Chinese Standard).

Groves, S. E.; Sanchez, R. J.; Lyon, R. E.; Brown, A. E. 1993. High strain rate effects for composite materials, in E. T. Camponeschi (Ed.). Composite Materials: Testing and Design, 162-176. https://doi.org/10.1520/STP12626S

Hufenbach, W.; Gude, M.; Ebert, C.; Zscheyge, M.; Horning, A. 2011. Strain rate dependent low velocity impact response of layerwise 3D-reinforced composite structures, International Journal of Impact Engineering 38(5): 358-368. https:// doi.org/10.1016/j.ijimpeng.2010.12.004

LSTC. 2007. LS-DYNA ${ }^{\circledR}$ Keyword User's Manual. Vol. 1. Version 971. Livermore Software Technology Corporation (LSTC). Available from Internet: http://lstc.com/pdf/lsdyna_971_manual_k.pdf

Jerabek, M.; Major, Z.; Lang, R. W. 2010. Strain determination of polymeric materials using digital image correlation, Polymer Testing 29(3): 407-416. https://doi.org/10.1016/j.polymertesting.2010.01.005

Brown, K. A.; Brooks, R.; Warrior, N. A. 2009. Characterizing the strain rate sensitivity of the tensile mechanical properties of a thermoplastic composite, JOM 61(1): 43-46. https://doi.org/10.1007/s11837-009-0007-9

Brown, K. A.; Brooks, R.; Warrior, N. A. 2010. The static and high strain rate behaviour of a commingled E-glass/polypropylene woven fabric composite, Composites Science and Technology 70(2): 272-283.

https://doi.org/10.1016/j.compscitech.2009.10.018

Liu, Q.; Lin, Y.; Zong, Z.; Sun, G.; Li, Q. 2013. Lightweight design of carbon twill weave fabric composite body structure for electric vehicle, Composite Structures 97: 231-238. https://doi.org/10.1016/j.compstruct.2012.09.052 
Ning, H.; Pillay, S.; Vaidya, U. K. 2009. Design and development of thermoplastic composite roof door for mass transit bus, Materials \& Design 30(4): 983-991. https://doi.org/10.1016/j.matdes.2008.06.066

Ning, H.; Janowski, G. M.; Vaidya, U. K.; Husman, G. 2007a. Thermoplastic sandwich structure design and manufacturing for the body panel of mass transit vehicle, Composite Structures 80(1): 82-91. https://doi.org/10.1016/j.compstruct.2006.04.090

Ning, H.; Vaidya, U.; Janowski, G. M.; Husman, G. 2007b. Design, manufacture and analysis of a thermoplastic composite frame structure for mass transit, Composite Structures 80(1): 105-116. https://doi.org/10.1016/j.compstruct.2006.04.036

Okoli, O. I. 2001. The effects of strain rate and failure modes on the failure energy of fibre reinforced composites, Composite Structures 54(2-3): 299-303. http://doi.org/10.1016/S0263-8223(01)00101-5

Parsons, E.; Boyce, M. C.; Parks, D. M. 2004. An experimental investigation of the large-strain tensile behavior of neat and rubber-toughened polycarbonate, Polymer 45(8): 2665-2684. https://doi.org/10.1016/j.polymer.2004.01.068

Parsons, E. M.; Boyce, M. C.; Parks, D. M.; Weinberg, M. 2005. Three-dimensional large-strain tensile deformation of neat and calcium carbonate-filled high-density polyethylene, Polymer 46(7): 2257-2265.

https://doi.org/10.1016/j.polymer.2005.01.045

Papadakis, N.; Reynolds, N.; Pharaoh, M. W.; Wood, P. K. C.; Smith, G. F. 2004. Strain rate effects on the shear mechanical properties of a highly oriented thermoplastic composite material using a contacting displacement measurement methodology - part A: elasticity and shear strength, Composites Science and Technology 64(5): 729-738. https://doi.org/10.1016/j.compscitech.2003.08.001

Reis, J. M. L.; Coelho, J. L. V.; Monteiro, A. H.; Da Costa Mattos, H. S. 2012. Tensile behavior of glass/epoxy laminates at varying strain rates and temperatures, Composites Part B: Engineering 43(4): 2041-2046. https://doi.org/10.1016/j.compositesb.2012.02.005

Şerban, D. A.; Weber, G.; Marşavina, L.; Silberschmidt, V. V.; Hufenbach, W. 2013. Tensile properties of semi-crystalline thermoplastic polymers: effects of temperature and strain rates, Polymer Testing 32(2): 413-425.

https://doi.org/10.1016/j.polymertesting.2012.12.002

Törnqvist, R.; Baser, B. 2002. Structural modules with improved crash performance using thermoplastic composites, SAE Technical Paper 2002-01-1038. https://doi.org/10.4271/2002-01-1038

Thattaiparthasarathy, K. B.; Pillay, S.; Ning, H.; Vaidya, U. K. 2008. Process simulation, design and manufacturing of a long fiber thermoplastic composite for mass transit application, Composites Part A: Applied Science and Manufacturing 39(9): 1512-1521.

https://doi.org/10.1016/j.compositesa.2008.05.017

UN. 1980. Uniform Provisions Concerning the Approval of: Vehicles with Regard to their Front and Rear Protective Devices (Bumpers, etc). Regulation No. 42-00. United Nations (UN). 15 p.

Vaidya, U. K.; Samalot, F.; Pillay, S.; Janowski, G. M.; Husman, G.; Gleich, K. 2004. Design and manufacture of woven reinforced glass/polypropylene composites for mass transit floor structure, Journal of Composite Materials 38(21):19491971. https://doi.org/10.1177/0021998304048418 